\title{
Duplex Stainless Steels-An overview
}

\author{
Dr. Sunil D.Kahar \\ Assistant Professor, Met.\& Mats. Engg. Dept., The M S University of Baroda,
}

\begin{abstract}
Stainless steel is one of the most important materials in the engineering world. The material's wide applications in chemical, petrochemical, off-shore, and power generation plants prove that it is one of the most reliable materials. The Newest fast growing family of stainless steels is duplex alloys. The ferritic-austenitic grades have a ferrite matrix intermix with austenite and in other words island of austenite in a continuous matrix of highly alloyed ferrite commonly called 'Duplex' stainless steel. Duplex stainless steel covers ferritic/austenitic $\mathrm{Fe}-\mathrm{Cr}-\mathrm{Ni}$ alloy with between $30 \%$ to $70 \%$ Ferrite .Due to high level of $\mathrm{Cr}$, Mo, and N steels shows high pitting \& stress corrosion cracking resistance in chloride-containing environments. Hence it is frequently used in oilrefinery heat exchangers \& typical applications where there is a risk for SCC and localized corrosion as a result of chloride-containing process streams, cooling waters or deposits. Modern duplex stainless steels have generally good Weldability. Due to a balanced composition, where nitrogen plays an important role, austenite formation in the heat affected zone (HAZ) and weld metal is rapid. Under normal welding conditions a sufficient amount of austenite is formed to maintain good resistance to localized corrosion where as too rapid cooling may result in excessive amounts of ferrite, reducing the toughness. Therefore, welding with low heat input in thick walled materials should be avoided. Welding methods, such as resistance welding, laser welding and electron beam welding, which cause extremely rapid cooling should also be avoided or used with extreme caution. Too slow cooling can in the higher alloyed duplex grades cause formation of inter-metallic phases detrimental to corrosion resistance and toughness.
\end{abstract}

\section{INRODUCTION}

Duplex stainless steels (DSSs), meaning those with a mixed microstructure of about equal proportions of austenite and ferrite have existed for more than 70 years. The early grades were alloys of chromium, nickel and molybdenum. The ternary phase diagram of the metallurgical behavior is shown in Fig.1. Dashed line shows solidification of typical duplex structure while red region denotes the mixture of ferrite $\&$ austenite. Fig. 2 shows the microstructure of Duplex stainless steels. A section through the ternary at $68 \%$ iron illustrates that these alloys solidify as ferrite, some of which then transforms to austenite as the temperature falls to about $1000^{\circ} \mathrm{C}$, depending on alloy composition[1].

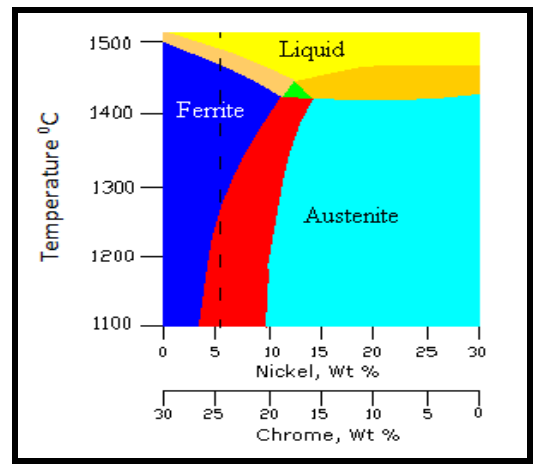

Fig.1 Fe-Cr-Ni Phase Diagram
There is little further change in the equilibrium ferrite austenite balance at lower temperatures. Thermodynamically, because the austenite is forming from the ferrite, it is impossible for the alloy to go past the equilibrium level of austenite. The main problem with Duplex is that it forms very easily brittle intermetalic phases, such as Sigma, $\mathrm{Chi}, \mathrm{R}$ and Alpha Prime .Prolonged heating in the range $350^{\circ} \mathrm{C}$ to $550^{\circ} \mathrm{C}$ can cause $475^{\circ} \mathrm{C}$ temper embrittlement The first wrought duplex stainless steels were produced in Sweden in 1930 and were used in the sulfite paper industry. These grades were developed to reduce the intergranular corrosion problems in the early high-carbon austenitic stainless steels.

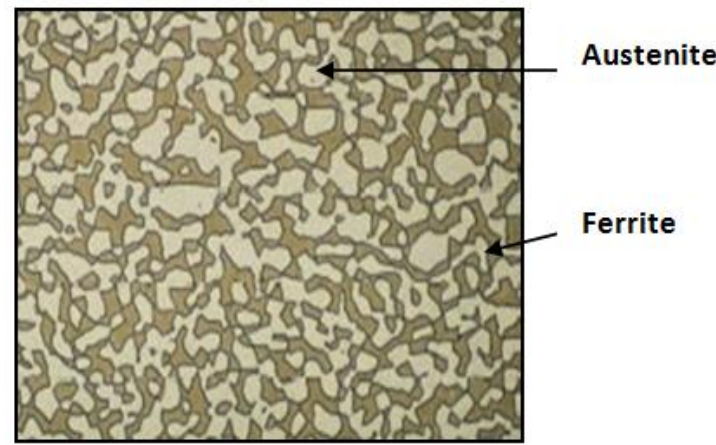

Fig.2 Microstructure of Duplex stainless steel 
Duplex castings were produced in Finland in 1930, and a patent was granted in France in 1936 for the forerunner of what would eventually be known as Uranus 50. It became obvious that a balance of ferrite and austenite had better resistance to chloride stress-corrosion cracking than a fully austenitic microstructure. Engineers have exploited this advantages of duplex over austenitic steels ever since. In France, the UR 50 grade with $20-35 \%$ ferrite (UNS S32404) was marketed in various product forms, including forging, for such industries as oil refinement, food processing, pulp and paper, and pharmaceutical. These steels were produced in high frequency induction furnaces using precisely weighed alloying additions. Partial vacuum ensured carbon removals, rudimentaryoxidation and restricted nitrogen ingress. Nevertheless, plate products remained sensitive to edge cracks.

\section{MODERN DEVELOPMENT of DUPLEX STAINLESS STEELS}

In the early 1980's, a second generation of duplex steels was introduced with improved welding properties mainly through nitrogen alloying. The most common duplex grade today is EN 1.4462 or 2205 (UNS S31803/S32205), which has a nominal composition of $22 \% \mathrm{Cr}, 5 \% \mathrm{Ni}, 3 \%$ $\mathrm{Mo}$, and $0.16 \% \mathrm{~N}$. This steel is used in a great number of applications in a wide variety of product forms. Many of the grades have become commonly known by a number that reflects their typical chromium and nickel contents,e.g. 2205 with $22 \%$ $\mathrm{Cr}$ and $5 \% \mathrm{Ni}$. The 2205 alloy is nitrogen enhanced duplex stainless steel alloy. The nitrogen serves to significantly improve the corrosion resistance properties of the alloy, which also exhibits a yield strength that is more than double that of conventional austenitic stainless steels; especially in the welded condition. Earlier duplex alloys have had moderate resistance to general corrosion and chloride stress-corrosion cracking but suffered a substantial loss of properties when used in the as welded condition. The 2205 duplex stainless steel provides corrosion resistance in many environments that is superior to the AISI Type 304, 316 and 317 austenitic stainless steels. This duplex stainless steel is often used in the form of welded pipe or tubular components, as well as a formed and welded sheet product in environments where resistance to general corrosion and chloride stress corrosion cracking is important. The increased strength creates opportunities for reduction in tube wall thickness and resists handling damage. Nevertheless, the extraordinary corrosion resistance (and other properties) of 2205 may be greater than is required in some applications. In certain SCC applications, while 2205 would provide an acceptable technical solution, it may not be an economical replacement alloy for Type 304, 316 or 317 stainless steel. The higher cost of 2205 is due primarily to the amounts of the alloying elements nickel (nominal 5.5\%) and molybdenum (nominal $3 \%$ ). Thus, it is desirable to provide a weldable, formable duplex stainless steel that has greater corrosion resistance than the Type 304,316 or 317 austenitic stainless steels, and has a lower production cost than the commonly used 2205 duplex stainless steel. The modern duplex stainless steels can be divided into four groups [Table 1].

Table- 1 : Chemical Composition of Duplex stainless steel

\begin{tabular}{|l|c|c|c|c|c|}
\hline Type & Cr \% & Ni \% & Mo \% & N $_{2} \%$ & PRE No \\
\hline Lean & $20-24$ & $1-5$ & $\mathbf{0 . 1 - 0 . 3}$ & $\mathbf{0 . 1 - 0 . 2 2}$ & $24-25$ \\
\hline Standard & $21-23$ & $4.5-6$ & $2.5-3.5$ & $\mathbf{0 . 1 - 0 . 2 2}$ & $33-35$ \\
\hline Super duplex & $24-29$ & $4.5-8$ & $2.7-4.5$ & $\mathbf{0 . 1 - 0 . 3 5}$ & $>40$ \\
\hline Hyper duplex & 27 & 6.5 & 5 & 0.4 & 49 \\
\hline
\end{tabular}

\subsection{Lean duplex stainless steel}

Lean duplex such as 2304, which contain no deliberate Mo addition. The lean alloy 2304 was developed to compete primarily with the austenitic AISI 316 grade, but with twice the yield strength and significantly better resistance to SCC. The weldability of 2304 duplex stainless is generally good when using slightly over-alloyed filler metal. The newly developed lean duplex grade LDX2101 has such improved weldability that also autogenously welding is possible and this material has contributed to the boom in the lean duplex market.

\subsection{Standard duplex stainless steel}

It is the dominant commercial duplex stainless steel which was developed in the 1970s, but was later optimized with higher nitrogen levels for improved weldability. The PRE of 2205 is about 33-35 resulting in a resistance to localized corrosion intermediate between the austenitic grade AISI 317 and the 5-6\% Mo super austenitic alloys. The weldability of this grade is good, but overmatching filler with increased nickel content, e.g. 2209, is normally required for optimum weld metal properties. 


\subsection{The super duplex stainless steel}

These grades were developed to withstand very aggressive environments to compete with super-austenitic and nickel base alloys. 2507 has, due to high molybdenum and nitrogen contents, a PRE of 42-43, and offers high mechanical strength and corrosion resistance in extremely aggressive environments such as chloride-containing acids. A consequence of the high alloy content, there is a risk of precipitation of inter-metallic phases, limiting the heat input and inter-pass temperatures when multi-pass welding. Overmatching filler with increased nickel content is required, e.g. 2509, to compensate element partitioning for optimum corrosion resistance.

\subsection{Hyper duplex stainless steel}

It was developed as a complement to 2507 with increased strength for use in even more aggressive conditions, such as in hot seawater, acidic chloride solutions and organic acids. SAF2707 HD can be welded with a matching filler wire of ISO2795L type. Due to the high alloying content, the hyper duplex alloys are somewhat more sensitive to secondary phase precipitation than the super duplex grades [2].

\section{DUPLEX STAINLESS STEELS: SOME USE AREAS}

Modern DSSs have been on the market for many years, including the super duplex grade, which was developed about 10 years ago. Due to the very fine-grained structure, nitrogen alloying, and ferrite and austenite mixture, the mechanical strength of DSSs is very high. DSSs may be used in many corrosive environments within the temperature range of approx $-50^{\circ} \mathrm{C}$ to less than $300^{\circ} \mathrm{C}$ in chloride containing process media or cooling water is common in the refining and petrochemical industry. Even at very low concentrations, the aggressive chloride ions may cause rapid failure if an improper material is selected. Chloride stress-corrosion cracking is a rapid form of corrosion, and can cause severe problems of hydrocarbon processing plants when occurring in equipment such as heat exchangers. Standard austenitic stainless steels of the AISI 300 series are sensitive to SCC in chloride-containing environments above approx $60^{\circ} \mathrm{C}$. This limits the use of these steels since many heat exchangers in the process industries are working at higher temperatures. It was observed that heat exchangers are by far the most critical piece of equipment and that DSSs in most cases are chosen as the first countermeasure to combat this form of corrosion. As regards pitting corrosion resistance duplex, alloys are as resistant as austenitic alloys with comparable PRE numbers.

\subsection{Duplex stainless steel in oil \& refinery application:}

DSSs are frequently used in oil-refinery heat exchangers where there is a risk for SCCand localized corrosion as a result of chloridecontaining process streams, cooling waters or deposits Crude Distillation. Atmospheric and vacuum distillation tower overhead systems are normally equipped with a large number of shelland tube heat exchangers and of air coolers. The corrosive conditions are complex and their severity is highly dependent on how successful the process control is, particularly the hydrochloric acid dew point. Corrosion control methods include water washing and injection of ammonia, caustic or amine inhibitors. In general, results obtained with these measures are quite variable, and experience at different refineries can be diverse. In many cases it has been difficult to keep control of the operational parameters over longer periods. This has led to premature failure, and in many cases a material upgrade has been the only solution for safe operation. In the case of upgrading, a highly qualified material is necessary while intermediate steps in the material selection range will not offer are liable solution. Failures have occurred on $22 \%$ $\mathrm{Cr}$ duplex in atmospheric overheads in conditions where severe ammonium chloride deposits have led to very short lifetime for carbon steels.Superduplex S32750 tubes, on the other hand, have been used successfully in both atmospheric and vacuum overhead condensers, showing that a high-alloyed super duplex can be a cost effective solution for such an application.Hydrotreating: In hydro treating, the main purpose is to remove sulfur from the intermediate and final refinery products. It has been observed that modern S31803 and S32304 DSSs have performed very well with no corrosion failure for some years. With older grade S31500, failures have been regarded as mainly attributed to bad welding and fabrication. These followed practices lead to excessive ferrite contents in the welded parts followed by hydrogen induced cracking. With modern duplex grades and use of welding procedures introducing $\mathrm{N}$ in the shielding gas, risk for excessive ferrite in the welds is low. This is shown by the fact that no failure has been reported to date with such modern types of duplex grades. 


\subsection{Duplex stainless steel in Petrochemicals Industries:}

Corrosive conditions experienced when processing many petrochemical compounds are less severe than the conditions experience in oil refineries. However, there are some major corrosion problems in the production of organic acids. In such conditions, duplex and super duplex come to their full advantage. For example, formic acid is the most aggressive of the organic acids. At temperatures up to $40^{\circ} \mathrm{C}$, AISI 304 may be used, while at higher temperature $316 \mathrm{~L}$ can be employed if the concentration is low. At higher concentration and temperatures above $80^{\circ} \mathrm{C}$, higher alloyed stainless steels must be used to keep the corrosion rate low. The DSSs S32803 / S32205 and S32750 have good resistance within certain limits. Desalination may be defined as the art of producing fresh potable water from a saline supply at reasonable cost and with reasonable reliability. There are different techniques to desalt water and for production of industrial and high quantity of potable water, distillation and reverse osmosis (RO) are the most used. Reverse osmosis can be either BWRO (brackish water RO) or SWRO (seawater RO). The major thermal processes are: Multi stage flash(MSFD) and multi effect distillation (MED)Poor experience of conventional austenitic 300 series grades such as 1.4404 (316L) and $1.4438(317 \mathrm{~L})$ for high-pressure parts in seawater plants has made highly alloyed grades of type S31254, e.g.254 SMO, more or less mandatory for large SWRO plants. However, the high cost of alloying elements, such as nickel and molybdenum, has presented a need to look for more effective options. One solution is a super duplex grade S32750, e.g. SAF 2507. It has almost the same resistance to pitting and crevice corrosion as $254 \mathrm{SMO}$, it has twice the strength, and the cost is far lower. The feed for BWRO plants is often higher in salinity than the second pass of SWRO plants and the grade has to be selected accordingly, but the duplex 2205 should be a natural option.

\subsection{Duplex stainless steel in Automotive Applications:}

Stainless Steel for Lightweight Design: Stainless steel is gaining increased interest from the automotive industry. The reason is the favorable combination of high strength and formability that many stainless steel grades provide. With a high energy absorption in crash situation added to this property combination, stainless steel can offer unique design opportunities for the automotive industry, opportunities that have just started to be explored. Lean duplex steels are the favorite because of their low cost.

\section{PROPERTIES \& BEHAVIOR OF DUPLEX STAINLESS STEELS a} 4.1. Mechanical properties of Duplex stainless steels

Duplex stainless steels have exceptional mechanical properties. They are listed for the standard duplex and super duplex grades in Table II. Their room temperature yield strength in the solution-annealed condition is more than double that of standard austenitic stainless steels not alloyed with nitrogen. This may allow the design engineer to decrease the wall thickness in some application. Despite the high strength (see fig. 3 \& 4) of duplex stainless steels, they exhibit good ductility and toughness. Compared with carbon steel or ferritic stainless steels, the ductile-to-brittle transition is more gradual. Duplex stainless steels retain good toughness even to low ambient temperatures, for example, $40^{\circ} \mathrm{C} / \mathrm{F}$; However, ductility and toughness of duplex stainless steels are in general lower than those of austenitic stainless steels (see fig. 3 \& fig.4). All four duplex stainless steels have good impact strength because of their optimized microstructure. The ductile tobrittle transition temperature is approximately $50^{\circ} \mathrm{C}$.Fatigue strength Owing to their high proof strength the duplex stainless steels also have very good fatigue strength[3-4].

Table -2: Minimum ASTM mechanical property limit for duplex and super duplex stainless steel

\begin{tabular}{|c|c|c|c|c|}
\hline Grade & UNS No & $\begin{array}{c}\text { Yield strength } \\
\mathbf{0 . 2 \%} \text { MPa (ksi) }\end{array}$ & $\begin{array}{c}\text { Tensile Strength } \\
\text { MPa (ksi) }\end{array}$ & $\begin{array}{c}\text { Elongatio } \\
\text { n in 2\% \% }\end{array}$ \\
\hline 2304 & S32304 & $400(58)$ & $600(87)$ & 25 \\
\hline 2205 & S32205 & $450(65)$ & $655(95)$ & 25 \\
\hline 2507 & S32750 & $\mathbf{5 5 0}(80)$ & $795(116)$ & 15 \\
\hline
\end{tabular}




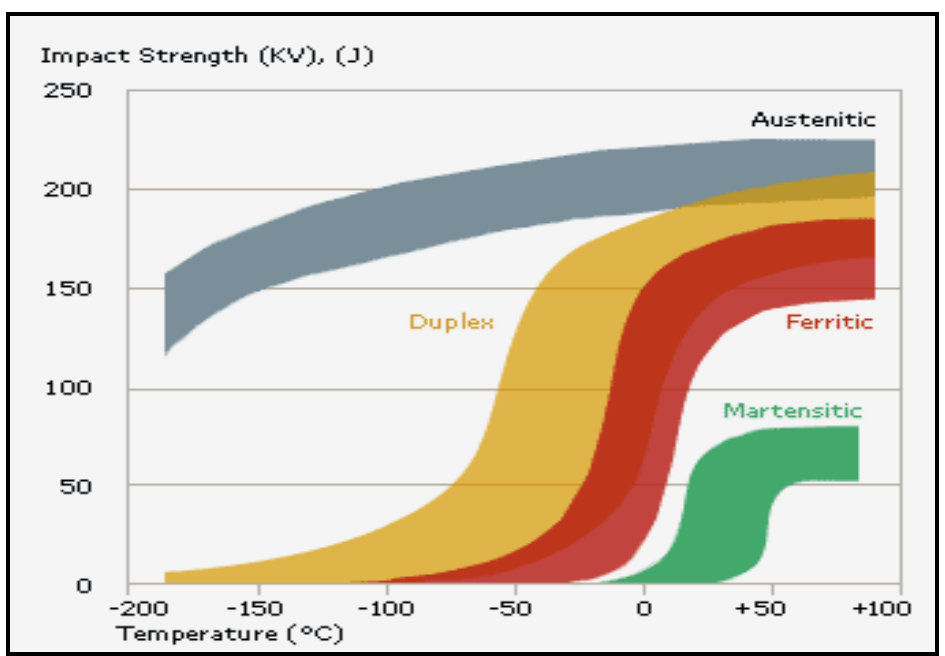

Fig. 3 Comparison of ductile to brittle transition temperature duplex stainless steel with other steel

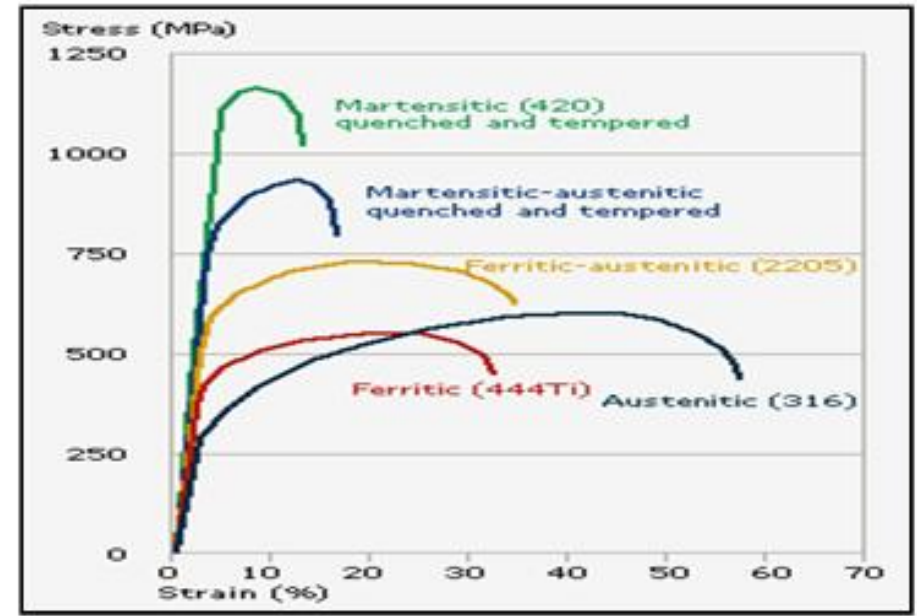

Fig 4 Comparison of tensile property duplex stainless steel with other steel.

4.2 Bending behaviour of Duplex stainless steels The initial force required for bending duplex stainless steels is higher than for steels of the ASTM 304L and 316L types. However, when the proof strength is exceeded, the plastic deformation takes place just as easily in the duplex as in the austenitic stainless steels. Duplex stainless steels can be cold-bent to approximately $20 \%$ deformation without subsequent heat treatment. Under service conditions where the risk of stress corrosion cracking starts to increase, heat treatment is recommended even after lower degree of cold bending. Heat treatment is carried out in the form of solution annealing or resistance annealing.

\subsection{Machining of Duplex stainless steels}

Being a two-phase material (austeniticferritic) a duplex stainless steel will present a different wear picture from that of single-phase austenitic steel of the ASTM 304/304L and 316/316 types. The cutting speed must be slightly lower than that recommended for ASTM 304/304L and TP 316/316L. It is recommended that a tougher insert grade is used for machining duplex stainless steels than that used for machining austenitic stainless steels. Built-up edges and chipping are to be expected in the whole cutting data area.

\subsection{Heat treatment of Duplex stainless steels}

Solution annealing If it is necessary to restore the duplex structure after a fabrication operation, this should be done at the following solution annealing temperatures followed by rapid cooling in air or water (some product forms may require a higher temperature .

\subsection{Physical metallurgy of Duplex stainless steels}

As already mentioned, an arc welding operation always means a more or less undesired heat treatment of the area close to the weld. This area, the heat affected zone (HAZ) or more accurately the high-temperature heat affected zone, is brought to a temperature, where the material is almost fully ferritic. At cooling a reformation of 
austenite starts in the grain boundaries and then continues in the ferrite grains forming a Widmanstätten type structure. When welding the DSS's the heat input and the cooling rate are important parameters. At too rapid cooling chromium nitrides are formed owing to the fact that at high temperatures the solubility of nitrogen in the ferrite is increased and at rapid cooling, when the solubility drops, chromium nitrides are formed. A limited amount of chromium nitrides does not have any effect on the properties of the weld unless they are located to the grains close to the surface. In that case, the corrosion resistance will be decreased because of the depletion of chromium. Thus, welding of heavy wall thicknesses with too low heat input must be avoided. If on the other hand the heat input is too high, precipitation of intermetalic phases can occur. It is mainly the ferrite that is prone to form intermetalic phases, above all s-phase, but also other intermetallics like c-phase, p-phase, l-phase, Rphase, Laves phase and carbides have been observed. The proneness to precipitation is directly proportional to the alloy content. One precipitate that can be as detrimental as chromium nitrides if it occurs in ferrite grains at the surface is secondary austenite. This phase forms at $800-950^{\circ} \mathrm{C}$ and can sometimes be seen in the upper parts of a root pass when the temperature conditions have been beneficial for this phase to form. As the secondary austenite is low in among others $\mathrm{Cr}$, Mo and $\mathrm{N}$, it means that its resistance to pitting corrosion is inferior to the surrounding matrix[5].

\subsection{Corrosion resistance of Duplex stainless steels \\ 4.6.1 General corrosion}

The duplex stainless steels' resistance to general corrosion is an important factor in prolonging the service life of process equipment. This makes them a superior alternative to standard austenitic grades such as ASTM 304Land 316L. The hyper-duplex grade SAF 2707 HD and superduplex SAF 2507 can also serve as alternatives to expensive Ni-based alloys and highly alloyed austenitic stainless steels in some applications .

\subsubsection{Pitting and crevice corrosion}

The pitting and crevice corrosion resistance of steel is primarily determined by the content of chromium, molybdenum and nitrogen. An index used to compare this resistance is the PRE (Pitting Resistance Equivalent). For duplex stainless steels the pitting corrosion resistance is dependent on the PRE value in both the ferrite phase and the austenite phase. This means that the phase with the lowest PRE value will set the limit for localized corrosion resistance of the steel. Critical Pitting Temperatures (CPT) in different environments the ranking given by the PRE value can generally be used to predict the performance of an alloy in chloride environments, as shown by the results of corrosion testing presented in the graphs on this spread. The critical pitting temperature can also be determined by electrochemical methods as the temperature at which a current increase occurs is associated with the breakdown of the passive layer at a certain potential. Pitting corrosion :The resistance to pitting corrosion is an important property of the duplex stainless steels and, of course, in a design it is important to make sure that the welds are not a limiting factor. The most common and convenient way to determine the critical pitting temperature (CPT) is by the ASTM G-48 A test. The role of nitrogen In a duplex stainless steel, nitrogen plays two important roles. The first one is to contribute to the resistance to pitting corrosion. The well-known PRE formula illustrates this PRE $=\mathrm{Cr} \%+3.3 \mathrm{Mo} \%+16 \mathrm{~N} \%$ The second one is to give the welds as fast and as complete austenite reformation as possible. Low solubility of $\mathrm{N}$ in the weld pool accounts for the loss of $\mathrm{N}$ in the weld surface. As already mentioned, this is the case especially with the TIG method and when pure Ar is used as shielding gas. On an average, when pure Ar is used, the loss is in the magnitude of $0.03-0.05 \%$. The loss of nitrogen also depends on the welding technique. As an example, when welding a butt joint in $6 \mathrm{G}$ position (fixed position $45^{\circ}$ angle), some welders can have a higher loss in the 3 to 9 o'clock positions than in the horizontal position. This is illustrated by table 13, page 10.Consequently, when maximum resistance to pitting corrosion is required, nitrogen bearing shielding and root gases should be used to compensate for the loss of nitrogen.

\subsubsection{Stress corrosion cracking}

The standard austenitic steels of the ASTM 304L and 316L types are prone to stress corrosion cracking (SCC) in chloride-bearing solutions at temperatures above $60^{\circ} \mathrm{C}$ $\left(140^{\circ} \mathrm{F}\right)$.Duplex stainless steels are far less prone to this type of corrosion. Practical experience and laboratory tests have shown their good resistance to stress corrosion cracking.

\subsubsection{Inter-granular corrosion}

In modern duplex stainless steels the chemical composition is balanced in such a manner that the reformation of austenite in the heataffected zone of the weld takes place quickly. This results in a microstructure that gives corrosion properties and toughness roughly equal to that of 
the parent metal. Welded joints in duplex stainless steels easily pass the intergranular corrosion test according to ASTM A262 Practice E (Strauss' test).

\subsubsection{Erosion corrosion}

Steels of the ASTM 316L type often suffer erosion corrosion if exposed to fl owing media containing highly abrasive solid particles, such as sand, or to media with very high flow velocities. Owing to their combination of high hardness and good corrosion resistance, duplex stainless steels display very good resistance under such conditions. Testing in sand-containing media has shown that duplex stainless steels have erosioncorrosion resistance better than corresponding austenitic stainless steels Fabrication.

\subsubsection{Hydrogen embrittlement in Duplex stainless steels}

How sensitive are the DSS's for hydrogen embrittlement and under what circumstances can it occur? Generally they are not, but cold cracking caused by hydrogen may occur under certain circumstances. Basically there are three conditions to be fulfilled for hydrogen cracking to occur, and all of them may sometimes be fulfilled in welding.

1. Presence of hydrogen.

2. Sensitive phase in the steel.

3. High tensile stress.

For the DSS's, it is the ferrite that is the "sensitive" phase. At a balanced 50/50 ferrite/austenite ratio, there are no signs of embrittlement, but as the amount of ferrite increases, the risk for hydrogen embrittlement will increase. There are different opinions about the ferrite level where the risk starts. Walker and Gooch at TWI have set the limit at $72 \%$, and somewhere between $70-75 \%$ the risk definitely increases. Of course, in order to get cold cracking also tensile stresses and hydrogen must be present. In MMA welding the hydrogen source could be moisture in the covering. The moisture can be present in two ways, either as crystal water in the minerals or as moisture pick-up from the air. The most efficient hydrogen source is moisture present as crystal water. Absorbed moisture from the air is more loosely bonded and most of it disappears during welding from the resistance heating of the core wire; from our investigation shows that there are small differences between dried electrodes and electrodes where the covering has picked up $1.4 \%$ of water. The hydrogen pickup is in the magnitude of 5-6 ml/100 $\mathrm{g}$ and too low to cause embrittlement. The hydrogen content was measured in a Stroehlein H-mat 251 equipment where the hydrogen was extracted at $950^{\circ} \mathrm{C}$, brought by argon to a thermistor cell (TCD) and determined by thermal conductivity. This method is more reliable than the mercury method which is quite sensitive to the sample surface.In SAW there is a more pronounced difference in hydrogen pickup between dried flux and moist flux. When compared with covered electrodes, the moist flux, which had a moisture content of $0.16 \%$, gave a hydrogen content in the weld deposit that was about 3 times higher. The flux shall always be dried at $350^{\circ} \mathrm{C}$ for 4 hours before welding. In TIG welding the hydrogen content can be controlled in a more precise way than in the processes described above. To get hydrogen in a TIG weld deposit hydrogen must be added to the shielding gas. Moisture in e.g. pure Ar gives a small contribution but is in reality of no interest. Sometimes argonhydrogen mixtures are used as shielding gas in order to increase the efficiency of the process. As this is a very effective way to introduce hydrogen into the weld deposit, it is not recommended for the DSS's. If the ferrite content is below 70-75\% nothing will happen, but at higher ferrite levels, cold cracking may occur. What will happen if hydrogen bearing root gas is used? The simple answer to that question is nothing! The pick-up of hydrogen from the root gas is negligible. This has been shown by our own studies and has also been confirmed by others[6].

\section{WELDING PROCESSES OF DUPLEX STAINLESS STEELS}

Modern duplex stainless steels have generally good weldability. The most common arc welding methods for stainless steels can be used with good results

- Gas tungsten-arc welding (GTAW or TIG)

- Gas metal-arc welding (GMAW or MIG/MAG)

- Shielded metal-arc welding (SMAW or MMA)

- Submerged-arc welding (SAW)

- Flux-cored arc welding (FCAW)

Due to a balanced composition, where nitrogen plays an important role, austenite formation in the heat affected zone (HAZ) and weld metal is rapid. Under normal welding conditions a sufficient amount of austenite is formed to maintain good resistance to localized corrosion. The metallurgical characteristics differ somewhat between the duplex grades, but the basic features are the same. Too rapid cooling may result in excessive amounts of ferrite, reducing the toughness. Therefore, welding with low heat input in thick walled materials should be avoided. Welding methods, such as resistance welding, laser welding and electron beam welding, which cause extremely rapid cooling should also be avoided or used with extreme caution. Too slow cooling can in the higher alloyed duplex grades cause formation 
of inter-metallic phases detrimental to corrosion resistance and toughness. Optimum weld properties can be obtained by closely following the directions below .The weld must be allowed to cool before next pass. Heat input should be kept within specific limits to secure a good microstructure in the weldment and hence optimum material properties. It is important that the heat input is adapted to the thickness of the material. Pre-heating is not necessary unless welding is carried out at temperatures far below room temperature, or if moisture is condensing on the material. Pre-heating with open flame should be avoided. ( Fig.5 and Fig.6) [7].

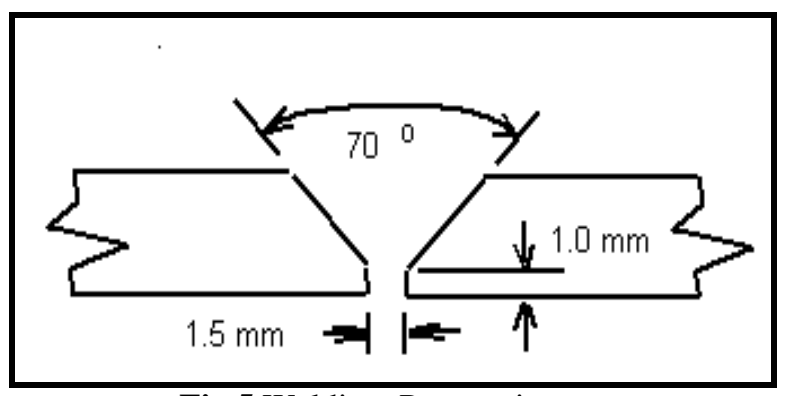

Fig.5 Welding Preparation

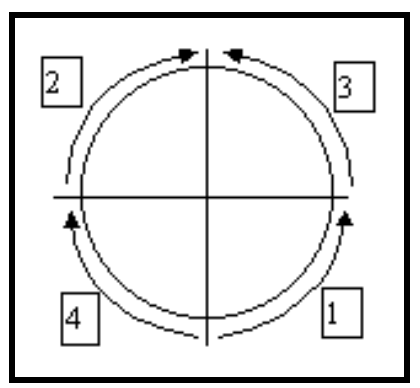

Fig.6 Welding Sequence

\subsection{Filler metals for the welding of the DSS's}

Fusion welding always means a local heat treatment of the welded joint and the parent metal close to the joint. As the heating cycle is very rapid, the weld metal will not be in equilibrium from a thermodynamic point of view. A filler metal with the same chemical composition as the parent metal would give a weld with excess of ferrite and poor mechanical and corrosion properties. Therefore, the filler metal contains more $\mathrm{Ni}$ in order to give a higher portion of austenite in the weld. For welding methods like GTAW nitrogen mixed into the shielding gas and the root purging gas provides improved resistance to localized corrosion. Post weld heat treatment (PWHT) is not normally required. If PWHT is required annealing should be carried out in accordance with the recommendations in the "Heat treatment" section below. Use filler material whenever possible. If filler material cannot be used in GTAW, for practical reasons, the shielding gas must contain nitrogen. In very aggressive environments SAF 2205 can be welded with the super-duplex filler materials 25.10.4.L or 25.10.4.LR to obtain the highest corrosion resistance possible in the weld. SAF 2507 can also be welded with 27.9.5.L in order to improve the corrosion resistance in aggressive environments. When SAF 2304 is used in oxidizing nitrate environments the filler material 23.7.L should be used[8].

\subsection{Welding methods}

The welding parameters used in different welding processes are in general the same for DSS's as for austenitic stainless steels. Manual metal arc welding (MMA) is mainly used for filler passes. Owing to its low sensitivity to strong winds, MMA is very suitable for welding on site. Repair welding is often done with this method because of its flexibility. Tungsten inert gas welding (TIG) is used for root passes and for the welding of thin-wall materials. The method gives a very pure weld deposit of high quality weld. Plasma arc welding (PAW) is also a suitable method for DSS's. It is mainly used by manufacturers of e.g. welded tubes and tube parts. If annealing cannot be made after welding, addition of nitrogen to the shielding or plasma gas is recommended, about $5 \% \mathrm{~N}_{2}$ in the plasma gas or $10 \% \mathrm{~N}_{2}$ in the shielding gas. Submerged arc welding (SAW) is mainly used for thick sections of sheet metal. It is a common method for the production of welded tubes. Metal inert gas welding (MIG) is used in fabrication when a high productivity is desired. Flux cored arc welding (FCAW) is like MIG welding a method which is used when a high productivity is desired .Filler metal is available for SAF 2304 and SAF 2205. Laser and electron beam (EB) welding process is used without the addition of filler metal and are not very suitable for the welding of duplex stainless steels as the welds will be very high in ferrite. Such a weld must be quench-annealed in order to get the correct structure. Friction welding of SAF 2205 type materials has successfully been made at TWI (The Welding Institute, UK). Spot and Seam welding being used on DSS's in order to improve the austenite reformation in spot welding, the electrodes can be kept in position after welding for a short-time resistance heating. As with laser and EB welding, autogeneous welding (welding without addition of filler metal) can be made as long as the whole construction can be quenchannealed after welding. In general, autogeneous welding is not recommended. If for some reason it has to be done, it must be followed by a full annealing cycle. If annealing is impossible, 
nitrogen addition to the shielding gas is strongly recommended.

\subsection{Joint preparation}

A proper joint preparation is important. For the duplex stainless steels, the same joint preparations can be used as those common for austenitic stainless steels. Before welding, the joint surfaces shall be degreased and free from any form of contamination.

\subsection{Shielding gases}

At TIG shielding and root gases may differ depending on the demands regarding corrosion resistance of the welded joint. In most cases pure argon will be satisfactory and give a corrosion resistance with enough margins. As the duplex stainless steels are nitrogen alloyed, a loss of nitrogen is inevitable in the surface area of the weld and in the parent metal area $0.2-0.5 \mathrm{~mm}$ from the weld if pure argon is used as shielding or root gas.Ferritic area in SAF 2507 weld owing to the loss of nitrogen. The most common way to prevent loss of nitrogen on the top side is to use a shielding gas containing nitrogen. Additions of $1-2 \% \mathrm{~N}_{2}$ to the argon are optimum. Higher additions should be avoided as they affect the tungsten electrode and destabilize the arc causing spatter. An increased risk for porosity is also noted. Nitrogen in the shielding gas will cause a nitrogen pick-up in the weld deposit. This will give a higher portion of austenite in the weld and a much lower risk for nitride precipitations in ferrite grains close to the surface of the weld. Other shielding gases can occur in TIG and PAW. In TIG welding 5\% hydrogen is sometimes added to the shielding gas in order to increase the efficiency of the arc. This is not recommended as the weld deposit will pick up a substantial amount of hydrogen, which may cause cold cracking if at the same time the ferrite content is high $(>70-75 \%)$. This subject will be further discussed under "Hydrogen embrittlement" below.MIG welding of DSS's is used more and more but there are only a few MIG wires on the market today with good welding properties In most cases the pulsed MIG process improves the result. If MIG welding is done, fully inert shielding gases like pure $\mathrm{Ar}$ or $\mathrm{Ar} / \mathrm{He}$ mixes shall be used. For FCAW the shielding gas $80 \% \mathrm{Ar}+20 \% \mathrm{CO}_{2}$ gives the best result. A duplex overlay weld will be embrittled at these temperatures. If allowed by the specification, this problem can be solved by stress relieving only after the first layer and not after the second. Stress relieving is sometimes specified in certain constructions. One example is overlay welds on tube sheets for heat exchangers, where a stress relieving has to be made at a temperature depending on the type of parent metal.

\subsection{Root gases:}

Generally pure argon is used for root protection, and for most applications this is satisfactory. However, as mentioned above, $\mathrm{Ar}$ leads to the loss of nitrogen at the surface of the root bead and at the parent metal $0-1 \mathrm{~mm}$ from the fusion line. Therefore, these areas will have inferior corrosion resistance. In order to keep a high pitting resistance nitrogen bearing root gas can be used. Ar with $2-3 \% \mathrm{~N} 2$ is not enough. At least $5 \%$ is needed. The best choice is $90 \% \mathrm{~N} 2+10 \% \mathrm{H} 2$ or pure nitrogen. As nitrogen is an excellent austenite stabilizer, a thin "skin" of austenite, about $20 \mathrm{~mm}$ thick, will form at the surface of the root bead and at the fusion line enhancing the corrosion resistance. Studies have shown that the pick-up from the root gas will be limited to the very surface area contrary to the case with shielding gas. For instance if that nitrogen is lost in the weld deposit, although the root gas contains $90 \% \mathrm{~N}_{2}+10 \% \mathrm{H}_{2}$ (pure $\mathrm{Ar}$ as shielding gas). Thus, $10 \%$ hydrogen will not cause any risk for hydrogen embrittlement. Post-weld treatment of welded joints und overlay Welds Preheating or post-weld heat treatment (PWHT) is not necessary or recommended for welding duplex stainless steels with the exception for autogenous welds, which is already discussed above. Stress relieving is sometimes specified in certain constructions. One example is overlay welds on tube sheets for heat exchangers, where a stress relieving has to be made at a temperature depending on the type of parent metal, see table A duplex overlay weld will be embrittled at these temperatures. If allowed by the specification, this problem can be solved by stress relieving only after the first layer and not after the second. Post-weld cleaning is important not only for the appearance but also for the corrosion resistance. The most efficient one is pickling followed by grinding. The finer the grains in the emery paper, the better the result. Wire brush or sandblasting will improve the corrosion resistance somewhat. Dissimilar joints In the fabrication of equipment in duplex stainless steels, there is often a need of welded joints between the duplex stainless steel and other steels, e.g. carbon steel, austenitic steel, etc. For dissimilar joints the duplex filler metal can be used in most cases, with the exception for joints between SAF 2507 and high alloyed austenitic grades, In dissimilar joints, the heat input shall be low and a low dilution by the parent metals is desired. suitable for mechanized welding and one good example is the butt-welding of tubes used in socalled umbilical's for the offshore industry. 
Umbilical's have different designs depending on what purpose they are intended for a quite common component is hydraulic tubing in wall thicknesses between 1.5-2.0 mm. Special attention must be paid to the heat input when welding these tubes in order to get an optimum structure. The use of filler metal and a heat input of $0.2-0.4 \mathrm{~kJ} / \mathrm{mm}$ is recommended. As post-weld cleaning, wire brushing with a stainless steel brush is often chosen as there is a limited amount of time between welding and coiling of the tube[9-10].

\section{CONCLUSION}

Duplex stainless steels have found widespread use because of an attractive combination of excellent mechanical properties, high corrosion resistance and relatively low cost compared with other high performance materials. A smaller grain size and a two phase austenitic ferritic microstructure that prevents grain growth, gives ,duplex stainless steels increased toughness and strength (in particular, very high proof strength Modern DSSs have been on the market for many years, including the super duplex grade, which was developed about 10 years ago. Due to the very finegrained structure, nitrogen alloying, and ferrite and austenite mixture, the mechanical strength of DSSs is very high.DSSs may be used in many corrosive environments within the temperature range of approx $-50^{\circ} \mathrm{C}$ to less than $300^{\circ} \mathrm{C}$. The modern duplex stainless steels have as good weldability as the austenitic stainless steels. The same type of joint preparations can be used for both, with the exception of one-sided butt welding where a slightly wider gap and a larger angle are preferred. For the DSS's too low and too high heat inputs should both be avoided, as both extremes can lower the corrosion resistance of the welded joint. There is wide range between the extremes and optimum results will be achieved by following the recommendations given above. Nitrogen additions to the shielding gas and the root gas can be used with advantage, when a higher corrosion resistance is desired in the weld, than normally can be obtained by pure argon. Especially in tube-to-tube sheet welding nitrogen is strongly recommended in order to make the weld less ferritic. The duplex stainless steels are not sensitive to hydrogen embrittlement. However, there is a risk for cold cracking under extreme conditions, namely if a low-energy weld has caused high-ferrite zones in the bead and HAZ (>70-75\% a) and if hydrogen is introduced by moisture in fluxes, electrode coverings or as hydrogen addition in the shielding gas.

\section{REFERENCES}

[1]. Sunil D.Kahar, Kiran B. Soni , Snehal Patel , Rajesh Mandani, Development of Welding Procedure for Super Duplex Stainless Steel Weld Overlay using ESSC Process and Evaluation of its Corrosion Properties, Proceedings of the international conference on corrosion in infrastructure and chemical industries (CICI2012) held during December 6-8, 2012 at Vadodara, India, organized by ITM universe, Vadodara, Gujarat technological university, Ahmadabad, ASM International, India chapter and NACE international gateway India section (2012). pp,1-2

[2]. Duplex Stainless Steels: Brief History and Some Recent Alloys Iris Alvarez-Armas* Instituto de Física Rosario -CONICET, Universidad National de Rosario, Bv. 27 de Febrero 210 BIS - 2000 Rosario - Argentina

[3]. 'Duplex Stainless Steels Properties and Applications' - 2205, Aalco

[4]. N. Ames, C. Fyre, K. Larsen, 'Improved corrosion resistance of SDSS weldments', stainless steel world 2004, pp 241-245

[5]. Elin M. Westin, Welding of Austenitic \& Duplex Stainless Steels - Overview www.outokumpu.com 06 December 2011|

[6]. Corrosion of Weldments CHAPTER 1 Basic Understanding of Weld Corrosion 2006 ASM International

[7]. How to weld Duplex Stainless Steel Avesta Welding www.avestwelding.com

[8]. Welding duplex stainless steel the ESAB way. A full range of consumables for all duplex grades and welding processes ESAB AB

[9]. Welding Duplex and Super duplex stainless Steels NIDI, Printed from Welding in the world,Vol.31,No 5,pp322- 343,1993

[10]. Sandvik duplex stainless steels- Sandvik Materials Technology, www. Smt.sandvik.com/globalassets/ global 